\title{
Warunki temperaturowe w czasie diagenezy piaskowców pensylwanu w rejonie Morza Baltyckiego
}

\begin{abstract}
Aleksandra Kozlowska ${ }^{1}$
Thermal conditions during diagenesis of Pennsylvanian sandstones in the Baltic Sea area. Prz. Geol., 67: 167-168; doi: $10.7306 / 2019.10$

A b s tract. The purpose of this study is to reconstruct the temperature conditions in the sediment during the diagenesis history of Pennsylvanian sandstones drilled in three deep boreholes in the Baltic Sea. These sandstones are represented by quartz and sublithic arenites and wackes, cemented by matrix and autigenic minerals. Among the autigenic minerals: quartz, clay minerals (kaolinite, dickite, illite) and carbonates (calcite, dolomite, ankerite) are the temperature indicators. The presence of dickite in the sediments indicates a temperature of about $120^{\circ} \mathrm{C}$. Quartz and carbonate crystallization temperatures, based on the analysis of fluid inclusions, are estimated to be in the range of $70-180^{\circ} \mathrm{C}$. The $\mathrm{K} / \mathrm{Ar}$ age of the fibrous illite that forms at the final stage of diagenesis (above $\left.100^{\circ} \mathrm{C}\right)$, was determined at $262 \pm 2$ to $247 \pm 4$ My, i.e. from the Middle Permian to the Early Triassic. It determines a length of the post-deposition period, when the deposits were permeable for pore fluids.
\end{abstract}

Keywords: temperature, autigenic minerals, diagenesis, sandstone, Pennsylvanian, Baltic Sea

Przedmiotem badań są piaskowce karbonu górnego z trzech otworów wiertniczych (K1-1/86, K9-1/89, L2-1/87) usytuowanych na Morzu Bałtyckim. Osady pensylwanu tworzyły się w środowisku przejściowym, od morskiego równi pływowej, do lądowego - rzecznego i jeziornego.

Celem pracy jest odtworzenie warunków temperaturowych działających w osadzie w czasie historii diagenezy, na podstawie uzyskanych wyników badań petrograficzno-mineralogiczno-geochemicznych piaskowców oraz opublikowanych danych osadów z obszaru Pomorza Zachodniego (Kozłowska, 2008).

W pracy zastosowano następujące metody badawcze: mikroskop polaryzacyjny, analizę barwnikową, katodoluminescencję, skaningowy mikroskop elektronowy, analizę w podczerwieni i XRD. Ponadto wykonano badania izotopowe obejmujące: oznaczenia węgla i tlenu w węglanach oraz datowanie wieku K/Ar w autigenicznym illicie.

\section{CHARAKTERYSTYKA PETROGRAFICZNA}

Piaskowce pensylwanu reprezentują najczęściej kwarcowe i sublityczne arenity oraz waki - od bardzo drobnoziarnistych do średnioziarnistych, lokalnie gruboziarnistych. Tekstura skały jest bezładna, lokalnie kierunkowa podkreślona ułożeniem blaszek łyszczyków, minerałów ilastych i hematytu. Głównym składnikiem szkieletu ziarnowego jest kwarc (monokrystaliczny przeważa nad polikrystalicznym), któremu towarzyszą zmienne ilości okruchów skał (metamorficzne typu łupków, rzadziej osadowe, bardzo droboklastyczne), skaleni (skaleń potasowy i wtórny albit) i łyszczyków (muskowit, biotyt). Spoiwo ma charakter porowo-kontaktowy i tworzą go: matriks (mieszanina detrytycznych minerałów ilastych i pyłu kwarcowego) oraz minerały autigeniczne reprezentowane przez kwarc, minerały ilaste, węglany, siarczany oraz hematyt.

\section{AUTIGENICZNE MINERALY A WSKAŹNIKI TEMPERATUROWE}

$\mathrm{Z}$ autigenicznych minerałów, rozpoznanych $\mathrm{w}$ piaskowcach karbońskich, wskaźniki temperaturowe stanowią: kwarc, minerały ilaste oraz węglany.

Kwarc występuje powszechnie, tworząc obwódki syntaksjalne na ziarnach kwarcu, które wypełniają przestrzeń porową częściowo lub całkowicie (ryc. 1A - patrz str. 128). Granica między kwarcem detrytycznym a cementem jest często podkreślona przez obecność hematytu i wodorotlenków żelaza, minerałów ilastych czy inkluzji fluidalnych. Cement i ziarna są bardzo dobrze widoczne w obrazie katodoluminescencyjnym, z powodu różnej barwy świecenia. Kwarc autigeniczny świeci w barwie ciemnoniebieskiej lub nie wykazuje świecenia, a kwarc detrytyczny - w barwie niebieskiej (ryc. 1A, B - patrz str. 128). Wydaje się, że występują dwie generacje obwódek kwarcowych. Cement kwarcowy jest zastępowany przez węglany oraz rozpuszczany. Badania inkluzji fluidalnych w piaskowcach na Pomorzu Zachodnim wykazały, że najczęściej występują inkluzje jednofazowe, co może sugerować temperaturę krystalizacji kwarcu ok. $50^{\circ} \mathrm{C}$. Natomiast pomiar temperatury homogenizacji w inkluzjach dwufazowych wskazuje na temperaturę krystalizacji w zakresie od ok. 70 do $180^{\circ} \mathrm{C}$ (Kozłowska, 2008).

Minerały ilaste są reprezentowane głównie przez kaolinit, dickit i illit oraz lokalnie minerały mieszanopakietowe, tj. illit-smektyt.

Kaolinit wypełnia przestrzenie porowe w piaskowcu (ryc. 1C - patrz str. 128). Ze względu na wykształcenie morfologiczne wyróżniono kaolinit robakowaty i blokowy (Kozłowska, 2004). W katodoluminescencji kaolinit wykazuje świecenie w barwie ciemnoniebieskiej. Kaolinit jest zastępowany przez węglany i przeobrażany w illit. W obrazie z mikroskopu elektronowego miejscami obserwowano

\footnotetext{
${ }^{1}$ Państwowy Instytut Geologiczny - Państwowy Instytut Badawczy, ul. Rakowiecka 4, 00-975 Warszawa; aleksandra.kozlowska@pgi.gov.pl
} 
przerosty kaolinitu robakowatego z kwarcu, co może sugerować ich jednoczesną krystalizację. Z obserwacji mikroskopowych wynika, że kaolinit blokowy tworzy się po kaolinicie robakowatym. Osborn i in. (1994) podają, że kaolinit robakowaty krystalizuje w temperaturze $25-50^{\circ} \mathrm{C}$, a blokowy w zakresie $50-80^{\circ} \mathrm{C}$. W formie blokowej oprócz kaolinitu występuje dickit (ryc. 1D - patrz str. 128). Obecność dickitu oraz przerostów kaolinitu z dickitem potwierdziła analiza w podczerwieni. Wraz ze wzrostem głębokości stwierdzono transformację kaolinitu w dickit, który jest uważany za paleotermometr i tworzy się w temperaturze ok. $120^{\circ} \mathrm{C}$ (Ehrenberg i in., 1993).

Illit wykształcony w formie włóknistej i igiełkowej obserwowano we wszystkich profilach badanych otworów wiertniczych, od głębokości $2200 \mathrm{~m}$. Narasta on na illicie blaszkowym, kaolinicie (ryc. 1C - patrz str. 128) oraz kwarcu i zarasta przestrzenie porowe w piaskowcu. Początkową temperaturę krystalizacji autigenicznego illitu szacuje się na ponad $100^{\circ} \mathrm{C}$ (Kantorowicz, 1990). Oznaczenia wieku K/Ar uzyskano w przedziale od $262 \pm 2$ do $247 \pm 4$ mln lat (Środoń i in., 2011).

Węglany są reprezentowane przez: kalcyt, dolomit, ankeryt i syderyt. Minerały te tworzą najczęściej spoiwo typu porowego, rzadziej podstawowe. Często zastępują ziarna skaleni i litoklastów oraz cementy, głównie kaolinit i kwarc autigeniczny.

Wyróżniono dwie generacje kalcytu: wczesną - pozbawioną domieszek, oraz późną, która zawiera mangan i niekiedy żelazo. W obrazie katodoluminescencyjnym czysty kalcyt nie wykazuje luminescencji, natomiast Mn/Fe-kalcyt wykazuje świecenie w barwach żółtych i pomarańczowych (ryc. 1E - patrz str. 128). Lokalnie cement kalcytowy charakteryzuje się budową pasową, co jest związane ze zmienną zawartością manganu i żelaza. Temperatura homogenizacji inkluzji dwufazowych w kalcycie piaskowców Pomorza Zachodniego sugeruje temperaturę jego krystalizacji - ok. $95-165^{\circ} \mathrm{C}$ (Kozłowska, 2008).

Dolomit tworzy kryształy automorficzne krystalizujące w przestrzeni porowej piaskowca. Charakteryzują się one budową jednorodną lub strefową, co jest związane ze zmienną zawartością żelaza i manganu (ryc. 1F - patrz str. 128). Miejscami obserwowano przejście od dolomitu do ankerytu, który tworzy strefy zewnętrzne kryształów dolomitu. Ze względu na wysoką zawartość żelaza ankeryt nie wykazuje świecenia w katodoluminescencji. Oznaczenia temperatury homogenizacji inkluzji w cemencie dolomitowym i ankerytowym w rejonie Pomorza Zachodniego wskazują na tworzenie się tych minerałów w temperaturze ok. $99-150^{\circ} \mathrm{C}$ (Kozłowska, 2008).

Oznaczenia izotopowe węgla $\delta^{13} \mathrm{C}$ w kalcycie, dolomicie i ankerycie mieszczą się w jednakowym zakresie od ok -3 do ok. $-10 \%$ PDB. Wskazują one, że węgiel pochodził z utleniania materii organicznej (Morad, 1998). Wartości $\delta^{18} \mathrm{O}$ dla kalcytu wynoszą od ok. -2 do ok. $-10 \%$ PDB, a dla dolomitu i ankerytu od ok. -4 do ok. $-9 \%$ PDB. Dane te $\mathrm{W}$ połączeniu $\mathrm{z}$ temperaturami krystalizacji minerałów węglanowych mogą sugerować, że dolomit wytrącał się z wody porowej o składzie wody meteorycznej, miejscami wzbogaconej w izotop ${ }^{18} \mathrm{O}$ (od powyżej -3\% SMOW), a kalcyt $\mathrm{z}$ wody o dodatnich wartościach $\delta^{18} \mathrm{O}$ (od powyżej $2 \%$ SMOW).

\section{PODSUMOWANIE I WNIOSKI}

Pierwsza generacja obwódek kwarcowych tworzyła się we wczesnym etapie diagenezy, w temperaturze ok. $50^{\circ} \mathrm{C}$, w $25-50^{\circ} \mathrm{C}$ krystalizował kaolinit robakowaty, a w $50-80^{\circ} \mathrm{C}$ - kaolinit blokowy. W przedziale tych temperatur wytracał się również dolomit. Cementacja kwarcem była kontynuowana i druga generacja powstała w wyższych temperaturach - ponad $70^{\circ} \mathrm{C}$, miejscami nawet w ok. $180^{\circ} \mathrm{C}$. $\mathrm{Z}$ cementów węglanowych Mn-kalcyt i ankeryt krystalizowały najpóźniej w historii diagenezy, w zakresie temperatur $90-160^{\circ} \mathrm{C}$. Jako ostatnie z minerałów ilastych tworzyły się dickit i illit włóknisty, w temperaturze ok. $120^{\circ} \mathrm{C}$.

Na podstawie badań materii organicznej (Grotek, 2005) maksymalna temperatura, jaka oddziaływała na analizowane osady podczas diagenezy, jest szacowana na ok. $140^{\circ} \mathrm{C}$, ale badania inkluzji fluidalnych sugerują, że mogła ona dochodzić do ok. $180^{\circ} \mathrm{C}$.

Oznaczenia wieku K/Ar krystalizacji illitu włóknistego (od $262 \pm 2$ do $247 \pm 4$ mln lat) wskazują, że krystalizacja tego minerału rozpoczęła się w środkowym permie i trwała do dolnego triasu. Ponieważ illit włóknisty jest minerałem tworzącym się w końcowym etapie diagenezy, to oznaczenie wieku początku jego krystalizacji określa czas, kiedy rozpoczęło się zamykanie przestrzeni porowych dla przepływu roztworów w osadzie.

Zamieszczone wyniki badań były finansowane $\mathrm{z}$ tematu 61.5701.1701.00.0. Autorka składa podziękowanie recenzentowi dr. Grzegorzowi Leśniakowi za uwagi do tekstu.

\section{LITERATURA}

EHRENBERG S.N., AAGAARD P., WILSON M.J., FRASER A.R., DUTHIE D.M.L. 1993 - Depth-dependent transformation of kaolinite to dickite in sandstones of the Norwegian Continental Shelf. Clay Mineral., 28 (3): 325-352.

GROTEK I. 2005 - Zmienność stopnia uwęglania rozproszonej materii organicznej z utworów karbonu w brzeżnej części platformy wschodnioeuropejskiej Polski. Biul. Państw. Inst. Geol., 413: 5-80.

KANTOROWICZ J. D. 1990 - The influence of variations in illite morphology on the permeability of Middle Jurassic Brent Group sandstones, Cormorant Field, UK North Sea. Marine Petrol. Geol., 7 (1): 66-74.

KOZŁOWSKA A. 2004 - Diageneza piaskowców górnego karbonu na pograniczu rowu lubelskiego i bloku warszawskiego. Biul. Państw. Inst. Geol., 411: 491-500.

KOZŁOWSKA A. 2008 - Diageneza a rozwój przestrzeni porowej w piaskowcach pensylwanu Pomorza Zachodniego. Biul. Państw. Inst. Geol., 430: 1-28.

MORAD S. 1998 - Carbonate cementation in sandstones: distribution patterns and geochemical evolution. Spec. Publ. int. Ass. Sediment., 26: $1-26$.

OSBORNE M., HASZELDINE R.S., FALLICK A.E. 1994 - Variation in kaolinite morphology with growth temperature in isotopically mixed pore - fluids, Brent Group, UK North Sea. Clay Minerals, 29 (4): 591-608.

ŚRODOŃ J. 2011 - Badania maksymalnych paleotemperatur ze stosunków illit/smektyt oraz datowania K/Ar diagenetycznego illitu. [W]: Poprawa P. (red.), Historia oraz diageneza zdarzeń termicznych w basenie polskim i jego osadowym podłożu - ich znaczenie dla rekonstrukcji procesów generowania węglowodorów. Nar. Arch. Geol. PIG-PIB, Warszawa. 


\section{Warunki temperaturowe w czasie diagenezy piaskowców pensylwanu w rejonie Morza Baltyckiego - patrz str. 167}

Thermal conditions during diagenesis of the Pennsylvanian sandstones in the Baltic Sea area - see p. 167

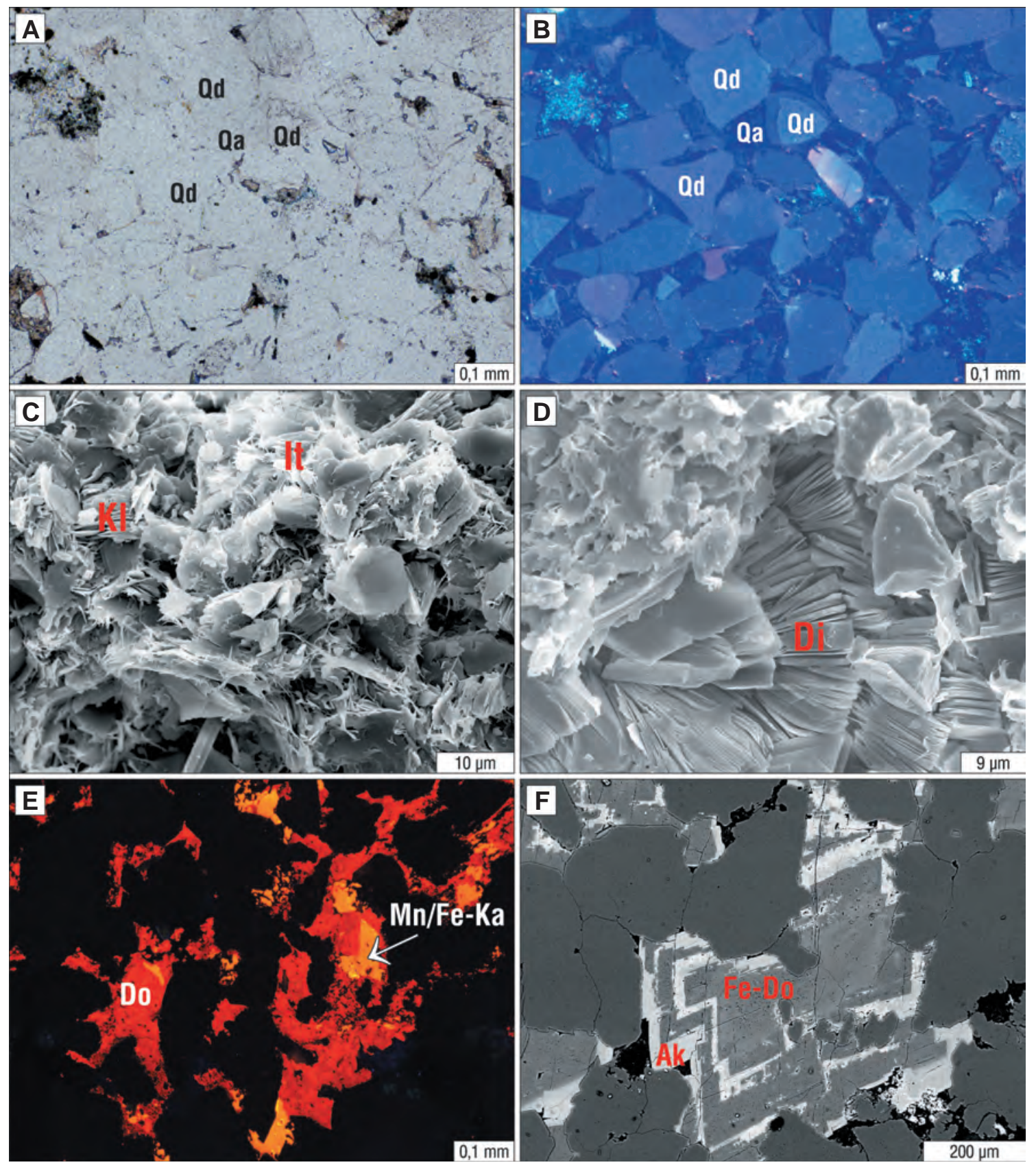

Ryc. 1. Zdjęcia wykonane w mikroskopie polaryzacyjnym (PL), w katodoluminescencji (CL) i skaningowym mikroskopie elektronowym (SEM, BSE). A - piaskowiec drobnoziarnisty, arenit kwarcowy; ziarna kwarcu (Qd) z obwódkami kwarcu autigenicznego (Qa); otwór K1-1/86, głęb. 3813,6 m, PL - bez analizatora. B - obraz w CL próbki z fot. A. Ziarna kwarcu (Qd) są niebieskie, a kwarc autigeniczny (Qa) wykazuje luminescencję w barwie ciemnoniebieskiej. C - kaolinit (K1) przeobrażany w illit (It) arenicie kwarcowym; otwór K1-1/86, głęb. 3104,9 m, obraz SE. D - dickit (Di) w arenicie kwarcowym; otwór K9-1/89, głęb. 3242,0 m, obraz SE. E - CL obraz fragmentu piaskowca z cementem węglanowy. Dolomit (Do) wykazuje luminescencję w barwie czerwonej, a Mn/Fe-kalcyt (Mn/Fe-Ka) w pomarańczowej; otwór K9-1/89, głęb. 3699,1 m. F - obraz BSE fragmentu piaskowca; budowa zonalna kryształów dolomitowych - strefy zbudowane z Fe-dolomitu (Fe-Do) i ankerytu (Ak); otwór K9-1/89, głęb. 3963,1 m

Fig. 1. Microphotographs taken in polarizing microscope (PL), cathodoluminescence (CL) and scanning electron microscopy (SEM, BSE). A - fine-grained sandstone, quartz arenite; quartz grains (Qd) with quartz overgrowths (Qa); borehole K1-1/86, depth $3813.6 \mathrm{~m}$, PL - without analyser. B - CL image of sample shown in phot. A. Blue luminescence of quartz grains (Qd) and dark blue of quartz overgrowths (Qa). C - kaolinite (Kl) altered into illite (It) in quartz arenite; borehole K1-1/86, depth $3104.9 \mathrm{~m}$, SEM image. D - dickite (Di) in quartz arenite; borehole K9-1/89, depth $3242.0 \mathrm{~m}$, SE image. E - CL image of sandstone fragment with carbonate cement. Red luminescence of dolomite (Do) and orange of $\mathrm{Mn} / \mathrm{Fe}$ calcite (Mn/Fe-Ka); borehole K9-1/89, depth $3699.1 \mathrm{~m}$. F - BSE image of sandstone fragment; zonal structure in dolomite crystals - zone built of Fe-dolomite (Fe-Do) and ankerite (Ak); borehole K9-1/89, depth $3963.1 \mathrm{~m}$ 